\title{
Sensitivity and Uncertainty analyses on a DELPHIN model: the impact of material properties on moisture in a solid brick wall
}

\author{
Naomi Grint ${ }^{1, *}$, Valentina Marincioni ${ }^{2}$, Clifford A Elwell $^{1}$ \\ ${ }^{1}$ UCL Energy Institute, Central House, 14 Upper Woburn Place, London, United Kingdom \\ ${ }^{2}$ UCL Institute for Environmental Design and Engineering, 14 Upper Woburn Place, London, United Kingdom
}

\begin{abstract}
This paper presents sensitivity and uncertainty analyses on a DELPHIN model, which is representative of a case study wall in real climatic conditions. Results of the Differential Sensitivity Analysis (DSA) show properties governing liquid water transported into, through and stored in the wall impact most on moisture accumulation, affecting relative humidity $(\mathrm{RH})$ outputs by $10-35 \%$ at three different locations in the wall. Parameters affecting vapour transport into the room also influence RH outputs at the inner location, but less than rain amount and rain exchange coefficient. A probabilistic uncertainty study is then used to explore key material functions, parameterised as four sets of co-ordinates and varied randomly. The correlation between the parameter inputs and the resulting change in $\mathrm{RH}$ is assessed. There are some surprising divergences from the DSA, including the significance of moisture storage in the plaster layer in the presence of liquid. Low correlation coefficients suggest numbers of variables could be reduced to further clarify the effects of these parameters, and interesting questions are raised on the parameterisation of material functions to represent the uncertainty in the characterisation of real walls.
\end{abstract}

\section{Introduction}

Hygrothermal models are useful in understanding the moisture risks of retrofitting structures, including adding insulation, but results can vary significantly due to uncertainty in input parameters, including material properties. This paper presents the results of sensitivity and uncertainty analyses on a hygrothermal model, exploring the impacts of material properties on moisture accumulation in the modelled wall. The study was based on a wall subjected to a long-term monitoring campaign [1].

Previous research has used hygrothermal uncertainty analyses to assess various structures including timber frame walls [2,3], a concrete roof [4], insulated brick walls [5,6] and porous material samples [7]. Uncertainty in material properties was found to impact on moisture accumulation even with relatively modest variations in parameter inputs. In this study, the variation in material properties of bricks, mortar and plaster being considered is greater, drawing on a large set of measured properties which could all feasibly represent the studied wall.

This study used the numerical simulation software DELPHIN [8], which is compliant with BS EN 15026 [9]. Differential sensitivity analysis (DSA) was undertaken, followed by a probabilistic sensitivity study using Monte Carlo Analysis (MCA) in which multiple parameters were varied simultaneously. The coefficient of correlation $(r$ value) was then calculated between each set of parameter inputs and the respective change in RH from a base model. The aim is to indicate the magnitude of influence of each parameter on the $\mathrm{RH}$ in the structure when the other parameters were also varied. This was used to study key material functions, parameterised as reduced sets of coordinates, in more detail.

\section{Modelling methods}

The model was constructed on the basis of a site survey, including visual inspection and drilling pilot holes. Indoor and outdoor temperature and $\mathrm{RH}$ site data were used alongside other climate data from local weather stations, as described in section 2.4. A one-dimensional discretisation mesh was used for the hygrothermal simulations performed in DELPHIN, as indicated in figure 1. This simplification allowed more than 100 models to be run in the DSA, and 1000s of models to be run for the MCA when using a high-performance computing facility [10]. Two dimensional models were also tested, giving no noticeable improvement in accuracy. Since a 2D mesh incurs significant computational cost, and also over-represents materials perpendicular to the direction of transport in the third dimension, 1D models were pursued.

The output cells match the measurement locations in the real wall. These are chosen to allow assessment of moisture across the bulk of a large uninsulated wall, as walls need to be better understood prior to the assessment of energy efficiency interventions. Parameter inputs to the DELPHIN model are categorised as material properties and functions, climate conditions, boundary conditions, and wall configuration (orientation and wall area).

\footnotetext{
* Corresponding author: n.grint@ucl.ac.uk
} 
Climate conditions are assigned to boundary conditions, which along with material properties are assigned to specific parts of the geometry.

For the DSA, base model central estimates for all parameters were used, then varied one at a time between maximum and minimum limits. For the first MCA study, approximately 2100 sets of parameters were generated based on uniform distributions for each, representing the widest known range of potential parameter inputs. Further MCA was undertaken on key material properties identified in the DSA study using triangular distributions, while holding the other parameters at constant central values. Triangular distributions constrain values within measured properties, whilst assigning a higher probability to the median values. The application of at least 20 continuous distributions, including log-normal and normal, was investigated, but were found to fit the observed data less well. Uncertainty in structure dimensions was not accounted for.

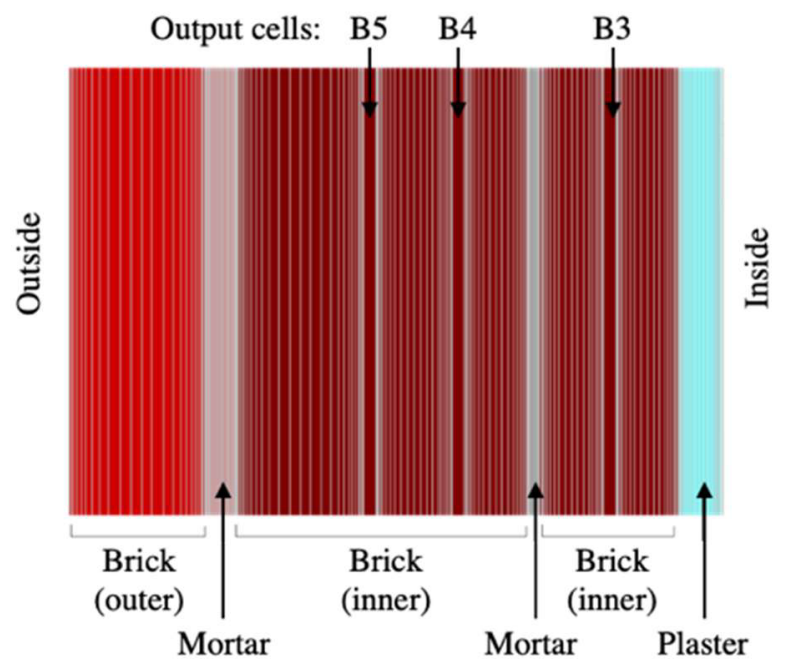

Fig. 1. DELPHIN Model set up - one-dimensional model

\subsection{Material properties}

Ranges of the material data inputs were drawn from the DELPHIN database as described in Table 1. The material data were filtered based on category name, bulk density and thermal conductivity. For bricks, the constraints for density and thermal conductivity were $1747_{-497}^{+353} \mathrm{Kg} \cdot \mathrm{m}^{-3}$, and $0.80_{-0.45}^{+0.26} \mathrm{~W} \cdot \mathrm{m}^{-1} \mathrm{~K}^{-1}$ respectively, which were based on a study of UK bricks [11]. For the mortar between bricks, and the plaster on the room side of the structure, there is greater uncertainty about material properties, which is reflected in the loose constraints on the density and thermal conductivity of the materials selected from the DELPHIN database (density: $1570_{-850}^{+850} \mathrm{Kg} \cdot \mathrm{m}^{-3}$, thermal conductivity: $\left.0.75_{-0.54}^{+1.35} \mathrm{~W} \cdot \mathrm{m}^{-1} \mathrm{~K}^{-1}\right)$.

For each of the material properties the distributions were tested for normality using an Anderson-Darling Normality test [12]; density was the only material property that was potentially normally distributed. Medians were therefore used instead of mean averages to indicate the most likely value for each material property.
Criteria for data rejection were considered for the material data based on values for the Absolute Deviation around the Median, which may be appropriate in place of standard deviations for non-normal data [13]. However, in the absence of clear justifications for scaling factors or rejection limits, all data were considered.

Correlations between material properties were assessed, and correlation coefficients of $>0.8$ identified. As expected, the moisture storage limits of the sorption isotherm are correlated, for example moisture content (MC) at capillary saturation, $\theta_{\text {cap }}$, with effective saturation, $\theta_{\text {eff }}$ (peak saturation without a vacuum), and $\theta_{\text {eff }}$ with $\theta_{\text {por }}$ (open porosity). Additionally, density appears to be correlated with thermal conductivity, and $\theta_{\text {eff }}$ and $\theta_{\text {por }}$. Some of the theoretically expected trends aren't evident in the data, such as liquid conductivity at

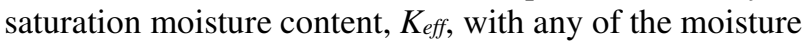
storage limits on the sorption isotherm, possibly due to differences in testing methods and scarcity of data. Initial tests indicated that the model is not sensitive to changes in density and thermal conductivity individually, so these correlations were not considered in the MCA analysis. Correlations in the moisture storage functions were addressed by using full functions derived from the DELPHIN database in the DSA model scripts.

Table 1. Summary of properties drawn from the DELPHIN database for brick $(\mathrm{N}=56)$ and plaster and mortar $(\mathrm{N}=101)$

\begin{tabular}{|c|c|c|c|}
\hline Property & Units & Brick & $\begin{array}{l}\text { Plaster / } \\
\text { Mortar }\end{array}$ \\
\hline Density, $\rho_{b}$ & $\mathrm{~kg} \cdot \mathrm{m}^{-3}$ & $1747_{-497}^{+353}$ & $1570_{-870}^{+850}$ \\
\hline Specific heat capacity, c & $\mathrm{J} \cdot \mathrm{kg}^{-1} \mathrm{~K}^{-1}$ & $900_{-66}^{+100}$ & $900_{-140}^{+553}$ \\
\hline Open porosity, $\theta_{\text {por }}$ & $\mathrm{m}^{3} \cdot \mathrm{m}^{-3}$ & $0.327_{-0.163}^{+0.084}$ & $0.341_{-0.249}^{+0.419}$ \\
\hline $\begin{array}{l}\text { Effective saturation MC, } \\
\theta_{\text {eff }}\end{array}$ & $\mathrm{m}^{3} \cdot \mathrm{m}^{-3}$ & $0.319_{-0.155}^{+0.091}$ & $0.288_{-0.196}^{+0.473}$ \\
\hline $\begin{array}{l}\text { Capillary saturation } \mathrm{MC} \text {, } \\
\theta_{\text {cap }}\end{array}$ & $\mathrm{m}^{3} \cdot \mathrm{m}^{-3}$ & $0.251_{-0.101}^{+0.015}$ & $0.240_{-0.140}^{+0.210}$ \\
\hline $\begin{array}{l}\text { Hygroscopic moisture } \\
\text { content at } \mathrm{RH}=80 \%, \theta_{80}\end{array}$ & $\mathrm{~m}^{3} \cdot \mathrm{m}^{-3}$ & $0.006_{-0.005}^{+0.052}$ & $0.032_{-0.031}^{+0.208}$ \\
\hline Thermal conductivity, $\lambda$ & $\mathrm{W} \cdot \mathrm{m}^{-1} \mathrm{~K}^{-1}$ & $0.80_{-0.45}^{+0.26}$ & $0.75_{-0.54}^{+1.35}$ \\
\hline $\begin{array}{l}\text { Water absorption } \\
\text { coefficient, } A_{W}\end{array}$ & $\mathrm{~kg} \cdot \mathrm{m}^{-2} \mathrm{~s}^{-0.5}$ & $0.170_{-0.169}^{+0.297}$ & $0.019_{-0.019}^{+0.611}$ \\
\hline $\begin{array}{l}\text { Vapor diffusion } \\
\text { resistance factor, } \mu_{\mathrm{dry}}\end{array}$ & - & $15.0_{-8.6}^{+153.0}$ & $18.0_{-12.5}^{+982.0}$ \\
\hline $\begin{array}{l}\text { Liquid conductivity at } \\
\text { saturation } \mathrm{MC}, \mathrm{K}_{\mathrm{eff}}\end{array}$ & S & $\begin{array}{r}2.0 \mathrm{e}^{-09+3.9 \mathrm{e}}-2.0 \mathrm{e}^{6} \\
\end{array}$ & $\begin{array}{r}6.4 \mathrm{e}^{-11+2.8 \mathrm{e}}-6.2 \mathrm{e} \\
\end{array}$ \\
\hline
\end{tabular}

\subsection{Parameterising material functions}

Moisture retention curves (MRCs) are defined by moisture retention properties measured in the overhygroscopic range, combined with sorption properties measured in the hygroscopic range $(<95 \% \mathrm{RH})$ using the Kelvin relation of capillary pressure to RH. The laboratory measurement processes are described in the literature $[14,15]$. Figure 2 shows the moisture retention and liquid water conductivity functions for 56 bricks, and the functions describing the maximum, minimum and median average values in the DSA. The range of MRCs is greater for the mortar and plaster samples than for the brick, which is representative of the greater uncertainty 
about these materials in the case study. However, the range of liquid conductivity functions are comparable despite the inclusion of different types of plaster and mortar, suggesting that very similar looking bricks may behave quite differently under moisture loads.
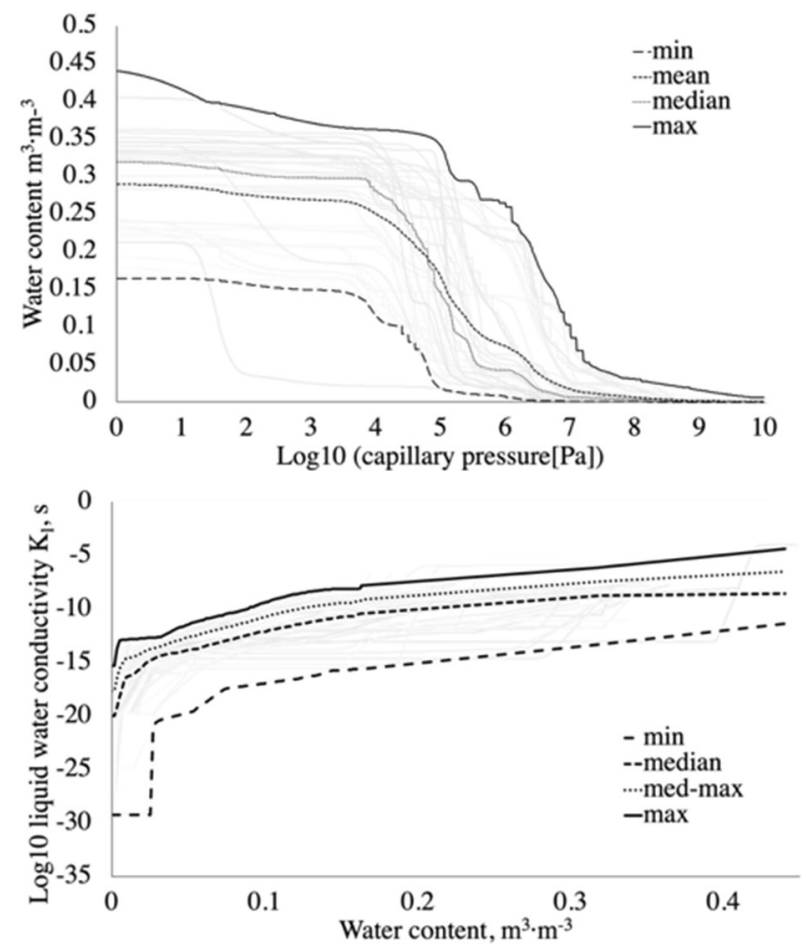

Figure 2. MRCs (top) and liquid water conductivity curves (bottom) for brick, $\mathrm{N}=56$. Light grey lines show the data for individual materials. The lower outlier in the MRC is a brick with a water repellent surface.

The impact of reducing the number of co-ordinates representing the MRC and liquid conductivity functions was investigated. In both cases simplifying to eight to ten sets of co-ordinates was possible without significantly impacting on the resulting $\mathrm{RH}$ predictions and reducing to four co-ordinates had a slightly greater impact depending on the location of the chosen co-ordinates. Figure 3 shows the results of a preliminary test on the MRC. There is approximately $10 \%$ difference in the $\mathrm{RH}$ peak using the inputs presented. In this case the grouping of the 4 coordinates of the MRC in the lower moisture range, leads to less storage in the brick and consequently more moisture reaching the measurement location B5.

A second preliminary study explored the impact of randomly changing the location of the four co-ordinates of the reduced MRC on RH at location B5 in the modelled wall and the results are shown in figure 4 . For the liquid conductivity function, the variation in co-ordinates had more varied effect on RH, so tighter constraints were chosen for this function.

These initial studies suggested that simplifying the material functions to four sets of co-ordinates had the potential to generate results similar to more complexly described functions and provided a compromise between parsimony and accuracy, but also that small changes in co-ordinate position had a big impact on RH outputs.
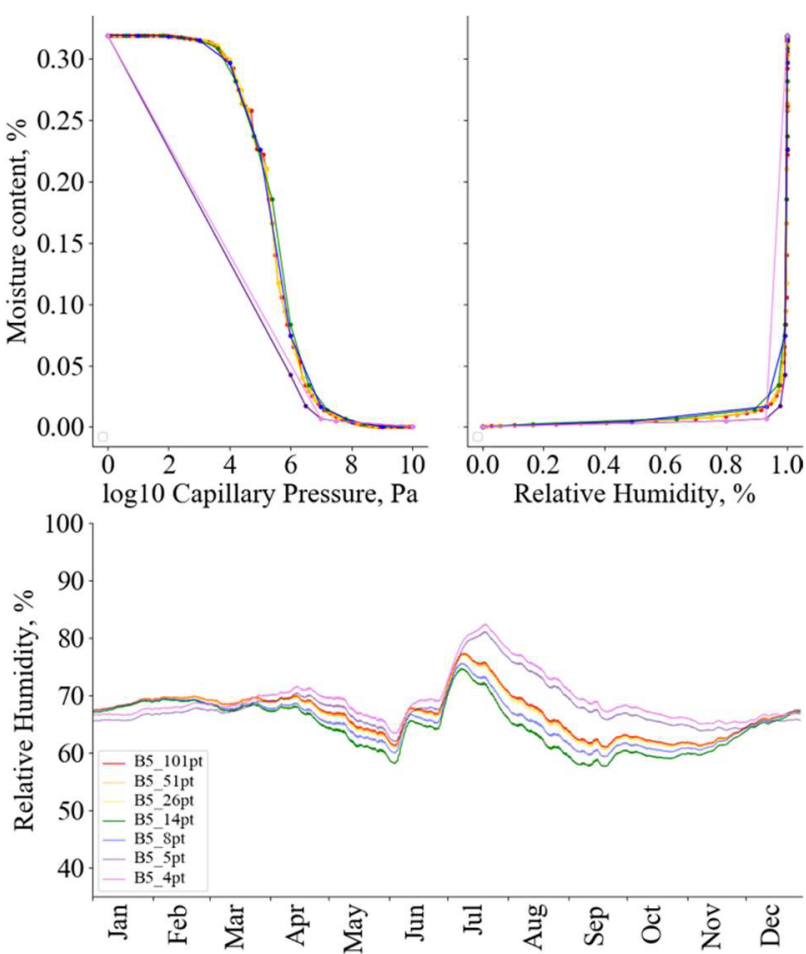

Figure 3. The impact of reducing the number of co-ordinates of the MRC (top left, with equivalent sorption isotherm on the right) on RH at location B5 in the modelled wall over the final year of simulation (bottom).
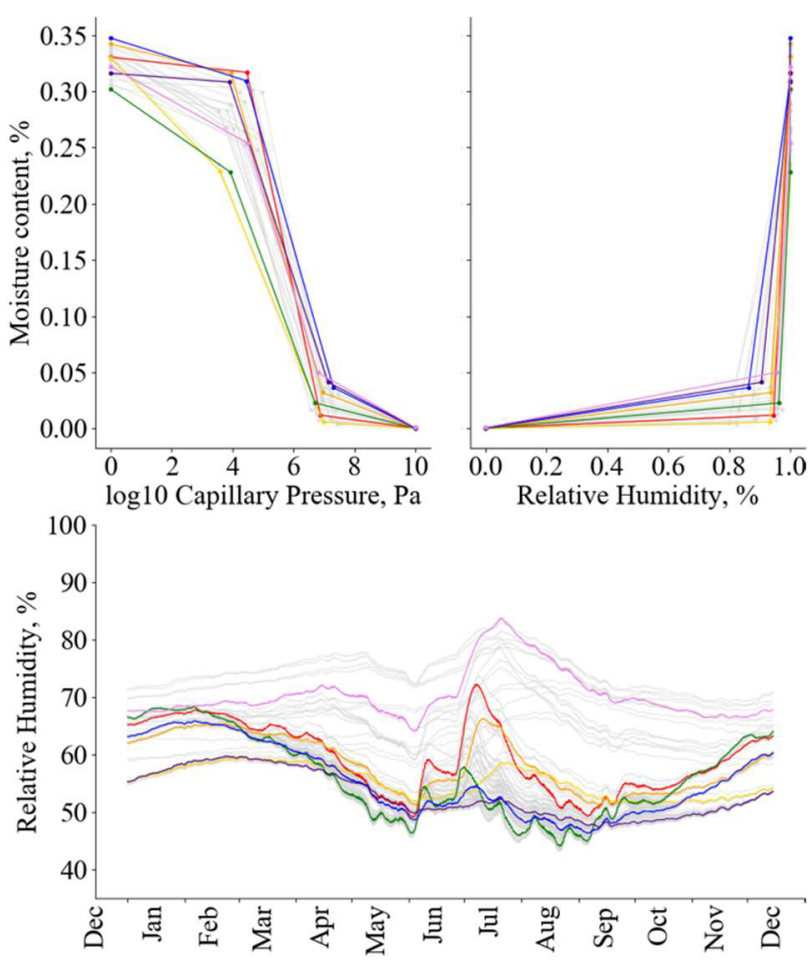

Fig. 4. The impact of changing the location of four co-ordinates of the reduced MRC (top left, with equivalent sorption isotherm on the right) on $\mathrm{RH}$ at location $\mathrm{B} 5$ in the modelled wall over the final year of simulation (bottom).

For the first MCA study the four co-ordinates were generated by setting $x$ and $y$ limits for each and sampling random values within a uniform distribution between these limits. For the second study they were generated 
using triangular distributions, with the median values fitting the median average functions from the DSA study. Tables 2 and 3 show the medians and limits used to generate the $x$ and $y$ co-ordinates in the reduced MRC and Liquid conductivity functions. Figure 5 shows the functions generated from these distributions.

Table 2. Moisture retention curve limits for $\mathrm{x}$ and $\mathrm{y}$ co-ordinates for brick (top) and plaster and mortar (bottom).

\begin{tabular}{|c|c|c|c|c|c|c|c|c|}
\hline & \multicolumn{4}{|c|}{$\begin{array}{c}\text { log capillary pressure, } \\
\mathbf{P}_{\mathbf{c}}[\mathbf{P A}]\end{array}$} & & \multicolumn{3}{|c|}{$\begin{array}{c}\text { Water content, } \\
{[\%]}\end{array}$} \\
\hline & & Min & Med & Max & & Min & Med & $\operatorname{Max}$ \\
\hline \multirow{4}{*}{ 党 } & $\mathbf{x}_{1}$ & & 0 & & $\mathbf{y}_{1}$ & 0.17 & 0.319 & 0.45 \\
\hline & $\mathbf{x}_{2}$ & 3.5 & 3.8 & 5.0 & $\mathbf{y}_{2}$ & 0.1 & 0.305 & 0.38 \\
\hline & $\mathbf{x}_{3}$ & 5 & 6.8 & 7.5 & $\mathbf{y}_{3}$ & 0 & 0.020 & 0.05 \\
\hline & $\mathbf{x}_{4}$ & & 10 & & $\mathbf{y}_{4}$ & & 0 & \\
\hline \multirow{4}{*}{ 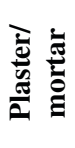 } & $\mathbf{x}_{1}$ & & 0 & & $\mathbf{y}_{1}$ & 0.17 & 0.265 & 0.47 \\
\hline & $\mathbf{x}_{2}$ & 3.5 & 4.7 & 5.5 & $\mathbf{y}_{2}$ & 0.08 & 0.225 & 0.47 \\
\hline & $\mathbf{x}_{3}$ & 6.5 & 8 & 8.5 & $\mathbf{y}_{3}$ & 0 & 0.020 & 0.15 \\
\hline & $\mathbf{x}_{4}$ & & 10 & & $\mathbf{y}_{4}$ & & 0 & \\
\hline
\end{tabular}

Table 3. Liquid conductivity function limits for $x$ and $y$ coordinates for brick (top) and plaster and mortar (bottom).

\begin{tabular}{|c|c|c|c|c|c|c|c|c|}
\hline & & \multicolumn{3}{|c|}{ Water content, [\%] } & & \multicolumn{3}{|c|}{$\begin{array}{l}\text { Liquid conductivity, } \\
\mathbf{K}_{1}[\mathbf{s}]\end{array}$} \\
\hline & & Min & Med & Max & & Min & Med & Max \\
\hline \multirow{4}{*}{ 苞 } & $\mathbf{x}_{1}$ & & 0 & & $\mathbf{y}_{1}$ & -20 & -17.8 & -16 \\
\hline & $\mathbf{x}_{2}$ & 0.003 & 0.01 & 0.02 & $\mathbf{y}_{2}$ & -17 & -14.5 & -13 \\
\hline & $\mathbf{x}_{3}$ & 0.1 & 0.14 & 0.17 & $\mathbf{y}_{3}$ & -11 & -9.5 & -8 \\
\hline & $\mathbf{x}_{4}$ & 0.17 & 0.319 & 0.45 & $\mathbf{y}_{4}$ & -10 & -7.44 & -6 \\
\hline \multirow{4}{*}{ 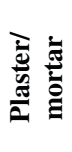 } & $\mathbf{x}_{1}$ & & 0 & & $\mathbf{y}_{1}$ & -30 & -21 & -16 \\
\hline & $\mathbf{x}_{2}$ & 0.003 & 0.03 & 0.04 & $\mathbf{y}_{2}$ & -30 & -18 & -16 \\
\hline & $\mathbf{x}_{3}$ & 0.07 & 0.14 & 0.17 & $\mathbf{y}_{3}$ & -15 & -13 & -11 \\
\hline & $\mathbf{x}_{4}$ & 0.17 & 0.265 & 0.47 & $\mathbf{y}_{4}$ & -18 & -10.4 & -6 \\
\hline
\end{tabular}
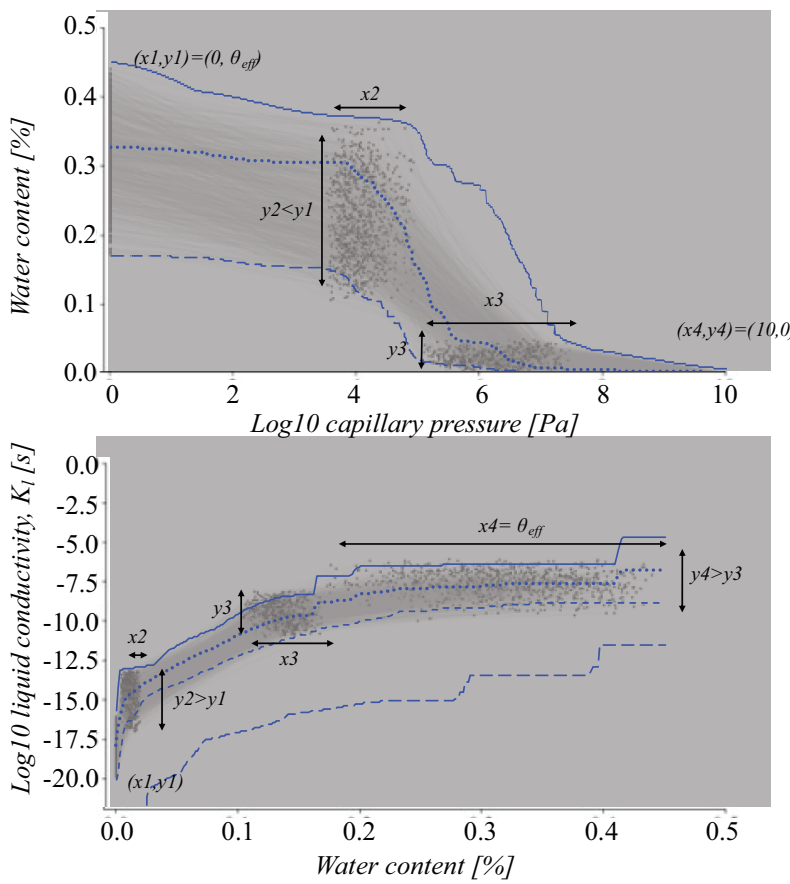

Fig. 5. Reduced moisture retention function (top) and liquid conductivity function (bottom) for brick using triangular distributions for four $\mathrm{x}$ and $\mathrm{y}$ co-ordinates. The light blue lines show the limits of the 56 brick measurements.
The effective saturation moisture content, eff, is used to set the maximum water content, corresponding to $y_{1}$ and $x_{4}$ in the MRC and Liquid conductivity function respectively. In the moisture retention curve, co-ordinates $\left(x_{2}, y_{2}\right)$ can be interpreted as the change in capillary pressure gradient at the capillary moisture content, cap, which is determined by the moisture content as the moisture front reaches the top of the sample during a capillary absorption test ISO 15148 [16]. Co-ordinates $\left(x_{3}, y_{3}\right)$ can be interpreted as change in capillary pressure gradient at the saturation limit of the hygroscopic range (corresponding to approximately $95 \%<<98 \%$ ). This can be described as a transition point tran, where the liquid water flux equals the vapour diffusion flux [17].

In the liquid conductivity function, the co-ordinates $\left(x_{3}, y_{3}\right)$ can be interpreted as change in liquid conductivity gradient at cap, and the co-ordinates $\left(x_{2}, y_{2}\right)$ can be interpreted as change in liquid conductivity gradient at tran (although the limits for cap and tran are different for the MRC in this study).

In the MRC, overlapping values in $y_{1}$ and $y_{2}$ were avoided by making $y_{1}=y_{2} \max$ if $y_{1}<y_{2 \max }$, and the median for $y_{2}$ was also reset if $y_{1}<y_{2}$ med. One potential improvement could have been to constrain the difference between $\mathrm{y}_{1}$ and $\mathrm{y}_{2}$ to take into account of the correlation in eff and cap, however this correlation may also be different in in-situ conditions. Overlapping values in the liquid conductivity function were handled similarly.

It is not clear how well international laboratory derived material functions represent the fabric of the UK built stock. In addition to measurement uncertainties, the potential differences in regional materials must be considered, alongside the inhomogeneity, material interface resistances and other imperfections present in real walls. These reduced material functions are loosely representative of laboratory derived material functions. However, considering the as built uncertainties in a real in-situ wall some simplification and deviation from laboratory measured values may be appropriate.

\subsection{Climate and boundary conditions}

The climate assumptions used in the model represented the conditions adjacent to the case study walls, as accurately as available data allowed. RH and temperature data were collected on site for the year 2016. Other climate data was extracted from the Met Office Integrated Data Archive System (MIDAS) database [18], which included rain, solar and wind data which were available from six different weather stations $10-15 \mathrm{~km}$ away from the site for the same year. A summary of all climate assumptions is given in Table 4. Maximum, minimum and mean average hourly values were used to form separate hourly climate input files for the DSA. For wind direction the maximum and minimums were generated by selecting the hourly wind direction closest to the wall orientation and furthest from the wall orientation (e.g. $180^{\circ}$ from the wall direction), after transposing the wind directions into their EW and NS vector components [19].

A summary of the medians and limits for boundary conditions is given in Table 5. The values and errors for 
inside and external vapour diffusion exchange coefficient, $i$ and $e$, are in line with Zhao [3], as were the inside and external heat transfer coefficient, $i$ and $e$, but these were not varied in the DSA as an initial study indicated that these had negligible impact on moisture transfer in this particular structure. The values for inside surface equivalent air layer thickness, $s d_{i}$, are set according to a study on paint properties, which included vapour permeable and non-vapour permeable paint finishes [20]. Rain exchange coefficient, $R$, describes the exposure to rain, taking into account shelter around the site, and the assumptions are derived from a number of sources [3, 21].

Table 4. Climate hourly input assumptions. Notes: 1) measured on site, the limits are more than the equipment accuracy in this case and indicate a potential change of use; 2) MIDAS Stations hourly average, minimum and maximum values; 3 ) shortwave component, derived from global irradiation.

\begin{tabular}{|c|c|c|c|}
\hline Climate condition & & Assumption & Notes \\
\hline Temperature external, $\mathrm{T}_{\mathrm{e}}$ & ${ }^{\circ} \mathrm{K}$ & Site $_{-5}^{+5}$ & \\
\hline RH external, $\Phi_{\mathrm{e}}$ & $\%$ & Site $_{-10}^{+10}$ & 1 \\
\hline Temperature internal, $\mathrm{T}_{\mathrm{i}}$ & ${ }^{\circ} \mathrm{K}$ & Site $_{-5}^{+5}$ & \\
\hline RH internal, $\Phi_{\mathrm{i}}$ & $\%$ & $\mathrm{Site}_{-20}^{+20}$ & \\
\hline Rain, R & $\mathrm{l} \cdot \mathrm{m}^{-2} \cdot \mathrm{h}^{-1}$ & Mean $_{- \text {Mean-Min }}^{+ \text {Max-Mean }}$ & 2 \\
\hline Wind direction, $\mathrm{W}_{\mathrm{d}}$ & $\begin{array}{l}{ }^{\circ} \text { from } \\
\mathrm{N}\end{array}$ & Mean $_{- \text {Mean-Min }}^{+ \text {Max-Mean }}$ & 2 \\
\hline Wind velocity, $W_{v}$ & $\mathrm{~m} \cdot \mathrm{s}^{-1}$ & Mean $_{- \text {Mean-Min }}^{+ \text {Max-Mean }}$ & 2 \\
\hline $\begin{array}{l}\text { Short wave radiation } \\
\text { (global), I }\end{array}$ & $\mathrm{W} \cdot \mathrm{m}^{-2}$ & Mean $_{- \text {Mean-Min }}^{+ \text {Max-Mean }}$ & 2 \\
\hline Direct radiation, Idir & $\mathrm{W} \cdot \mathrm{m}^{-2}$ & Mean $_{- \text {Mean-Min }}^{+ \text {Max-Mean }}$ & 3 \\
\hline Diffuse radiation, $\mathrm{I}_{\mathrm{dif}}$ & $\mathrm{W} \cdot \mathrm{m}^{-2}$ & Mean $_{- \text {Mean-Min }}^{+ \text {Max-Mean }}$ & 3 \\
\hline
\end{tabular}

Table 5. Boundary condition input assumptions. Notes: 1 ) as per Zhao [3]; 2) values from [20]; 3) various sources [3,21]; 4) default values.

\begin{tabular}{llcc}
\hline Boundary condition & Units & Assumption & Notes \\
\hline $\begin{array}{l}\text { Vapour diffusion exchange } \\
\text { coefficient inside, } \beta_{\mathrm{i}}\end{array}$ & $\mathrm{s} \cdot \mathrm{m}^{-1}$ & $3.0 \mathrm{e}^{-08}+4.5 \mathrm{e}^{-09}$ & 1 \\
$\begin{array}{l}\text { Equivalent air layer thickness } \\
\text { internal, sd }\end{array}$ & $\mathrm{m}$ & $1.32_{-1.28}^{+7.68}$ & 2 \\
$\begin{array}{l}\text { Heat transfer coefficient } \\
\text { internal, } \alpha_{\mathrm{i}}\end{array}$ & $\mathrm{W} \cdot \mathrm{m}^{-2} \mathrm{~K}^{-1}$ & 8 & 1 \\
$\begin{array}{l}\text { Vapour diffusion exchange } \\
\text { coefficient external, } \beta_{\mathrm{e}}\end{array}$ & $\mathrm{s} \cdot \mathrm{m}^{-1}$ & $2.0 \mathrm{e}^{-07}+3 \mathrm{e}^{-08} \mathrm{e}^{-08}$ & 1 \\
$\begin{array}{l}\text { Heat transfer coefficient } \\
\text { external, } \alpha_{\mathrm{e}}\end{array}$ & $\mathrm{W} \cdot \mathrm{m}^{-2} \mathrm{~K}^{-1}$ & 25 & 1 \\
$\begin{array}{l}\text { Rain exchange coefficient, } \alpha_{\mathrm{R}} \\
-\end{array}$ & $0.65_{-0.35}^{+0.35}$ & 3 \\
$\begin{array}{l}\text { Minimum rain temperature, } \\
\mathrm{R}_{\mathrm{t}}\end{array}$ & ${ }^{\circ} \mathrm{K}$ & $-2.0_{-1.0}^{+1.0}$ & 4 \\
$\begin{array}{l}\text { Absorption coefficient of the } \\
\text { building surface, } \alpha_{\mathrm{K}}\end{array}$ & - & $0.75_{-0.15}^{+0.15}$ & 1 \\
$\begin{array}{l}\text { Ground reflection coefficient, } \\
\alpha_{\text {albedo }}\end{array}$ & - & $0.55_{-0.35}^{+0.35}$ & 1 \\
\hline
\end{tabular}

\section{Results and discussion - DSA}

\subsection{Ranking of most influential parameters}

Figure 6 shows the relative effects of changes to individual parameters in relation to the results of the base model. These are measured as the minimum and maximum differences from the base model during the final year of simulation, using the lower limits and upper limits of each parameter. The figure shows the 16 parameters with the maximum absolute affect for either the upper or lower extreme parameter inputs, for the location B3 (left) and B5 (right). B3 is closer to the internal surface of the wall and B5 is closer to the external surface, but still central in the wall and within the material defined as 'inner brick', as shown in figure 1.

The chosen extremes for the rainfall, $R$, appears to have the largest effect at both positions in the modelled wall. The extremes for $W_{V}$ and $W_{D}$, the other climate parameters contributing to wind driven rain (WDR), also have a significant impact, decreasing at the location further away from the external surface. The climate files were generated using hourly average, minimum and maximum values from six MIDAS weather stations, which may overstate the extremes. The top two graphs in Figure 7 show the effect of these climate parameters over the final year of simulation. The increased rain amount results in close to $100 \% \mathrm{RH}$ in location B5 for the whole year. The change in wind direction, $W_{D}$, towards the orientation of the wall is not constant, having most impact in the summer months, whereas the increased wind velocity, $W_{V}$, has a more constant impact over the whole year.
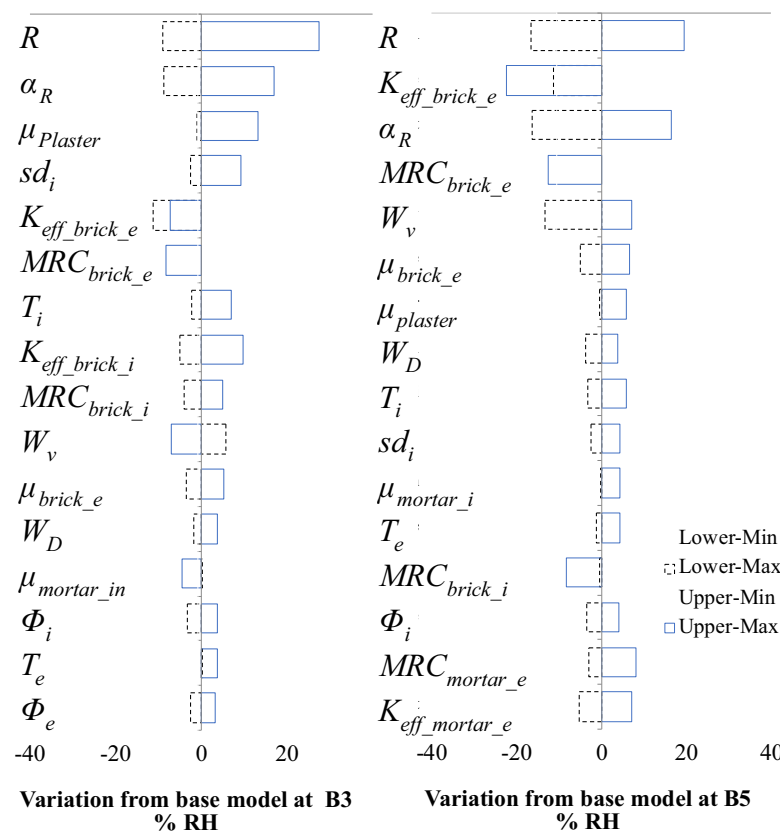

Fig. 6. The ranked effects of the upper and lower parameter inputs on $\mathrm{RH}$, relative to the results of the 'base' model at location B3 (left) and B5 (right). The shaded bars show differences between the minimum and the lines show differences between the maximum annual relative humidity, using the upper and lower limits of each parameter. 


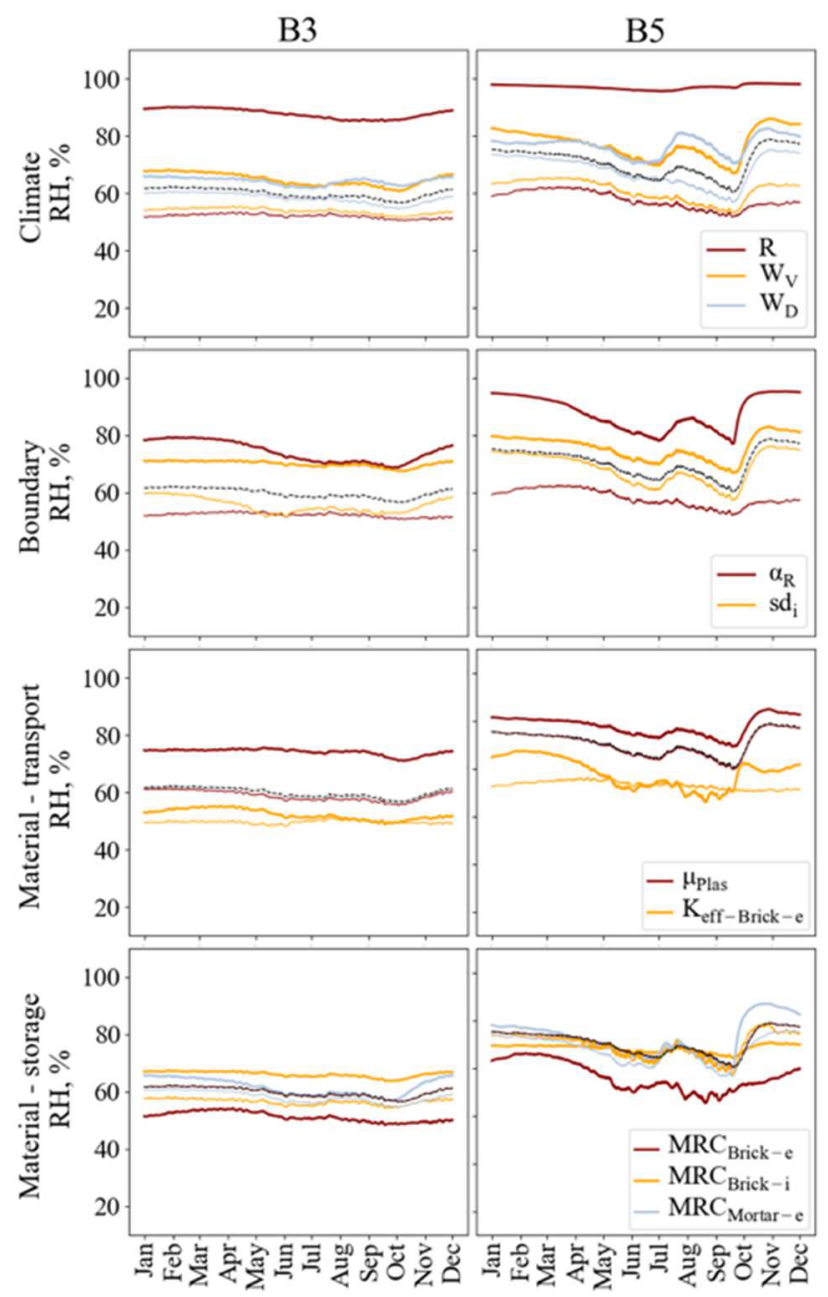

Fig. 7. Relative humidity over the final year of simulation at location B3 (left) and B5 (right) for key climate, boundary and material parameters. The thicker lines show the effects of the upper input values and the thinner lines of the lower input values for each parameter. Dashed black lines show the 'base model' for each location (these appear to be solid where the plot associated with one of the parameters matches the base model).

Of the boundary parameters, the rain exchange coefficient, $R$, which determines any reduction in WDR penetrating the wall due to local sheltering has the most significant impact. At the upper limit, $R$, results in a similar increase in maximum and minimum RH at both locations in the wall, whereas at the lower limit the reduction in the maximum annual $\mathrm{RH}$ is more apparent at the outer location. The equivalent air layer thickness inside, $s d_{i}$, affecting vapour exchange with the room, has a predictably greater impact at B3 compared to B5.

Of the material transport properties, liquid conductivity at saturation moisture content, $K_{\text {eff, }}$ of the outer brick, which is used to scale the liquid conductivity function, was found to have most impact at the outer location, changing the $\mathrm{RH}$ at location $\mathrm{B} 5$ by more than $20 \%$ RH during parts of the year, with only rain amount having a greater effect of all the parameters.

Both the maximum and minimum extremes of the liquid conductivity function result in a reduced $\mathrm{RH}$ compared to the base model (median). At B5 the lower input results in a very slight annual fluctuation around $60 \% \mathrm{RH}$ whereas the upper limit results in a greater reduction in the summer months and less of a reduction in the winter months with a sudden increase in autumn. This is surprising but may indicate that the increase in moisture transport also facilitates the removal of the moisture from the wall during summer months. The effects at location B3 are similar but much reduced in magnitude and more constant. The upper input for the vapour diffusion resistance factor of the plaster on the inside surface of wall, Plas, was found to have more effect at location B3 than any properties of the external brick, increasing $\mathrm{RH}$ by up to $15 \%$. Some effect is also seen at location B5, but as expected this is less variable and of a reduced magnitude over the year.

Of the material properties related to moisture storage, the moisture retention curve of the external brick, $M R C_{\text {Brick_e }}$, has most impact at both location B3 and B5, however the lower input values appear to have negligible effect compared to the base model input values. This is surprising but may indicate that the base model assumptions result in very little moisture storage in the outer brick. The upper limit results are similar to that of liquid conductivity at saturation moisture content, $K_{\text {eff, }}$, and may suggest that the modelled liquid remains in the external brick before evaporating outwards during the summer part of the simulation.

The upper input for the moisture retention curve for the inner bricks, $M R C_{\text {Brick_i }}$, has the effect of reducing the magnitude of fluctuations in both locations. (The 'inner brick' is the material at both locations - see figure 1). The lower input has less effect in overall magnitude but results in higher frequency changes to RH in location B5. Increases to moisture storage in the outer layer of mortar $\left(M R C_{\text {mortar_e }}\right)$ have a non-linear effect and in the opposite direction to the effects of changes to the storage function of the outer brick during peak moisture in autumn. This indicates a critical depth in the outer wall, either side of which stored moisture will be transported inwards towards the room, or to the outside.

\section{Results and discussion - MCA}

For the probabilistic sensitivity analysis using MCA, two studies were carried out. In each study, at least 2000 random values were generated for all parameters, using the uniform distributions for the first study and triangular distributions for the second study, as discussed in section 2. For the second study two material functions were varied for five materials in the wall, with the median value used for all other parameters. In both studies the coefficient of correlation ( $r$ values) were calculated between each set of parameter inputs and the corresponding change in $\mathrm{RH}$ outputs at each of the three locations (B3, B4 and B5) compared to the DSA base model, for each hour during the final year of simulation. The maximum and minimum $r$ values over this year were compared.

\subsection{All parameters - uniform distributions}

The MCA using uniform distributions led to very low correlation coefficients, generally below \pm 0.05 , over the 
final year of the simulation. The ranking revealed some quite different results from the DSA study, most notably that the rain amount, $R$, and rain exposure coefficient, $R$, are not within the 20 parameters with inputs most correlated to the RH outputs, whereas several heat transport and storage parameters that had not been significant in the DSA results are within these 20 parameters. This may be caused by the overrepresentation of extremes by using uniform distributions combined with the variation of 130 parameters. A reduction in studied parameters, more sophisticated distributions and more model runs may be required to counteract this.

\subsection{Material functions - triangular distributions}

The results of the MCA on the material functions are shown in figure 8 . The correlation coefficients are still less than 0.1 , as there are still approximately 60 parameters being varied in the parameterisation of the two material functions for the five material layers modelled in the wall. The full range of $\mathrm{RH}$ results over the final year of simulation are shown in figure 9.

Some of the results in figure 8 have clearer physical explanations, such as that for co-ordinate $x_{3}$ of the outer brick moisture retention curve, which may be interpreted as the capillary pressure associated with the moisture content at the transition point between the hygroscopic and over-hygroscopic range, tran. A higher value would indicate an increase in storage potential in this moisture range. The negative correlation coefficient suggests this increased storage potential results in less liquid transport through the outer brick, and therefore a lower RH further into the wall.

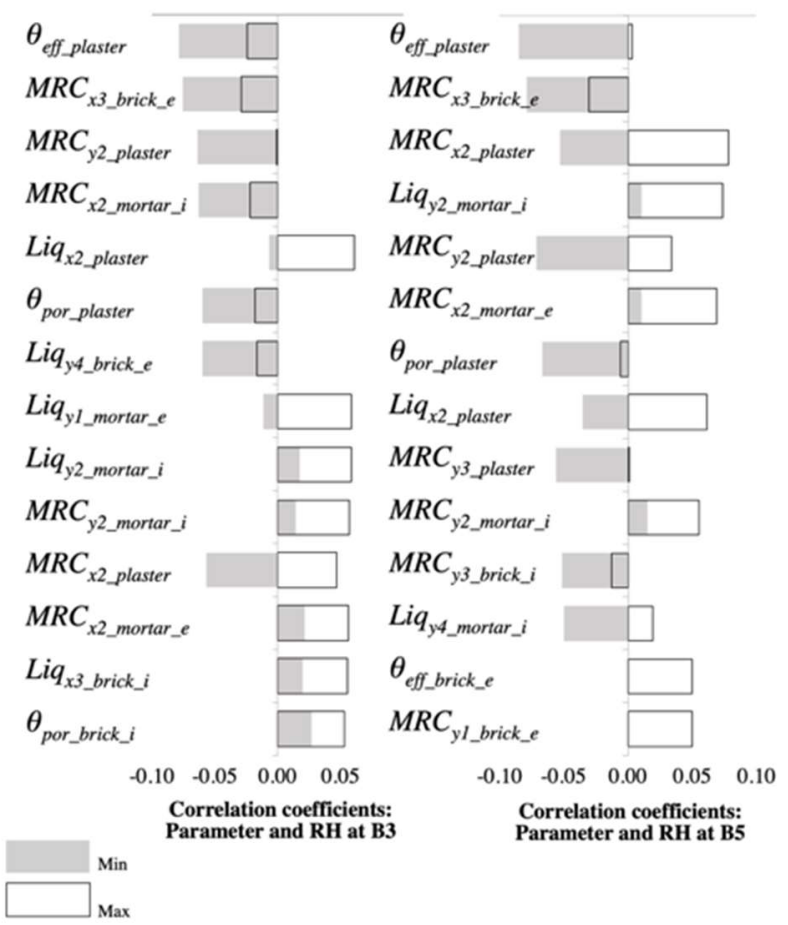

Fig. 8. Minimum and maximum correlation coefficient over the final year of the simulation for the MCA on material functions generated using triangular distributions.
Some of the results in figure 8 are unexpected, such as the relatively high absolute correlation coefficients for the effective saturation moisture content of the internal plaster, eff_plaster - which sets the maximum of both the moisture retention curve (on the $y$-axis) and the liquid conductivity function (on the $x$-axis), and $x_{3}$ of the plaster MRC - which can be interpreted as capillary saturation moisture content, cap. These both influence moisture storage in the over-hygrothermal range, which is surprising, given the relatively low $\mathrm{RH}$ outputs at location B3 shown in figure 9. However, the range of co-ordinates for tran, leads to some modelled cases in which the overhygroscopic range is reached at just over $80 \% \mathrm{RH}$, so liquid water could be present in the pores of the plaster in these cases. The negative correlation would imply that the potential for liquid movement and storage in the plaster aids the movement of moisture away from location B3 into the room side of the wall. This would also depend on adequate liquid conduction through the brick and mortar layers between location B3 and the plaster.

It is also worth noting that one of the parameters affecting the liquid conductivity of the mortar sited between B3 and B5, liqy2_mortar_i, is positively correlated to the change in $\mathrm{RH}$ at both locations. Also, liquid conductivity of the outer brick, which was indicated to be a key parameter in the DSA study did not feature in the 20 parameters in figure 8 . This may be due to the tighter constraints described in section 2.3. It is also possible that further reduction in studied parameters and more model runs may still be required.

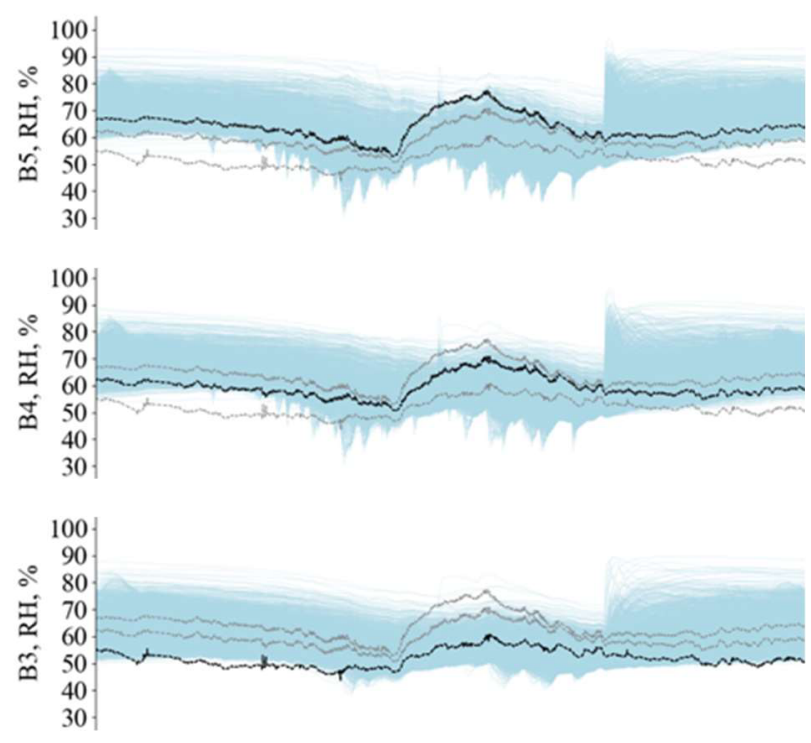

Fig. 9. All RH results from the MCA on material functions of the five materials for the final year of simulation. Plotted against site measurements at location B5 (top), B4 (middle) and B3 (bottom) respectively.

\section{Conclusion}

This paper presents sensitivity and uncertainty analyses on a DELPHIN model, which is representative of a case study wall. The results highlight that plausible parameter estimates can lead to model outputs that are significantly 
different from the observed performance. Uncertainty in material properties was found to have a significant impact on predicted moisture accumulation in the modelled wall; greater than has been found by previous studies. In the DSA study the properties and functions were drawn from laboratory derived properties in the DELPHIN database, which may be a conservative representation of the uncertainties in describing the character of a real in-situ wall, due to the movement and storage of moisture and air in the unknown pore structure, larger cavities and material interfaces.

The DSA results showed that rain amount, rain exchange coefficient, and the liquid conductivity and moisture storage functions of the outer brick, impact most on moisture accumulation, and affect the RH outputs by $10-35 \%$ at different locations in the wall. Parameters affecting vapour transport into the room also appear to have a significant influence at the inner location, but less than rain amount and rain exchange coefficient.

The MCA explored the effects of all parameters varied simultaneously by assessing the correlation between the parameter inputs and the change in resulting $\mathrm{RH}$ from a base model. The study using the uniform distributions to generate inputs for all parameters highlighted the need to use more sophisticated distributions, especially when a large number of parameters are investigated. A more focused study on key material functions, parametrised as a reduced set of co-ordinates, enabled the ranking of maximum absolute coefficients of correlation over a year. This study yielded some surprising results, some which appeared to be more physically plausible than others. A further reduction in studied parameters with more model runs would be useful to clarify some of these effects. The increased significance of moisture storage and liquid conductivity properties of plaster in the results of this study compared to the DSA was notable. The combined influence of the vapour resistance of the plaster and the vapour resistance of the surface finish would be also be useful to study in more detail, especially in an insulated wall.

The MCA study on material functions focussed on moisture retention and liquid conductivity, as these functions had the greatest and least constant effects on moisture over the final year of the simulation in the DSA study. The functions were reduced to a small number of co-ordinates which represented key moisture transition points in the functions, which is similar to simplified models proposed by previous studies [22]. The parameters considered for the reduced functions are not related to detailed studies of the material pores, e.g. by mercury intrusion [23], but assume that imperfections on site might be more significant than pore structure. The simplification may also allow for moisture storage and liquid transport to be included in parameter estimation studies, which may further our understanding of the behaviour of brick walls.

The site data that was used as the basis for the study is presented in the partner paper [1]. This paper has briefly explored how the effects of parameter changes relate to the real data. This is far more complex than assessing the relationship with a base model and could be explored in greater depth.

\section{References}

1. N. Grint, C. Elwell 12th Nordic Symposium on Building Physics (2020 - partner paper by the same author)

2. M. Salonvaara, A. Karagiozis, A. Holm, Buildings VIII / Moisture Model Validation-Principles (2001)

3. J. Zhao, R. Plagge, A. Nicolai, HVAC\&R Research 17 (2011).

4. A. Holm, H. Künzel, Building and Environment 37, 883-889 (2002)

5. V. Marincioni, G. Marra, H. Altamirano-Medina, H. Building and Environment, 137, 257-267 (2018).

6. A. Tijskens, H. Janssen, H, S. Roels, S. 4th WTA International PhD Symposium, 149-156 (2017)

7. T. Defraeye, B. Blocken, J. Carmeliet, Chem. Eng. Research and Design, 91(1), 36-42 (2013)

8. www.bauklimatik-dresden.de/delphin/

9. BS EN 15026:2007 Hygrothermal performance of building components and building elements. Assessment of moisture transfer by numerical simulation

10. UCL Myriad. https://www.ucl.ac.uk/research-itservices/services/research-computing-platforms

11. C. Hall, A. Hamilton, Materials and Structures 48, 1265-1271 (2015)

12. T. Anderson, D. Darling, J. American Statistical Association 49, 765-769 (1954)

13. C. Leys, O. Klein, P. Bernarda, L. Licata, J. Experimental Social Psychology 49, 764-766 (2013)

14. R. Plagge, G. Scheffler, A. Nicolai, ASHRAE Buildings X International Conference (2007)

15. G. Scheffler, R. Plagge, International Journal of Heat and Mass Transfer 53, 286-296 (2010)

16. C. Feng, H. Janssen, Building and Environment 134, 21-34 (2018)

17. J. Grunewald, P. Häupl, M. Bomberg, Journal of Building Physics 26, (2003)

18. NCAS British Atmospheric Data Centre, Met Office Integrated Data Archive System (MIDAS) Land and Marine Surface Stations Data (1853-current) (2019)

19. United States Environmental Protection Agency, EPA-454/R-99-005 (2000)

20. S. Roels, J. Carmeliet, Nordic Symposium on Building Physics (NSB 2005), 609-616 (2005)

21. B. Blocken, J. Carmeliet, Wind and Structures 5(5), 441-462 (2002)

22. C. Rode, P. Hansen, K. Hansen, Technical University of Denmark. Byg Rapport, No. LFV-214 (1990). referenced in G. Scheffler, Dresden University of Technology, Thesis, 47 (2008)

23. S. Roels, J.Carmeliet, H. Hens, O. Adan, Journal of Building Physics 27 (2004) 